\title{
Influence of graphene nanoplatelets on mechanical properties and adhesive wear performance of epoxy-based composites
}

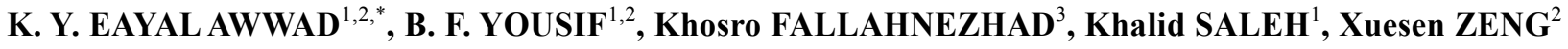 \\ ${ }^{I}$ Faculty of Health, Engineering and Sciences, University of Southern Queensland, Toowoomba, QLD, Australia \\ ${ }^{2}$ Centre for Future Materials, University of Southern Queensland, Toowoomba, QLD, Australia \\ ${ }^{3}$ School of Mechanical and Mining Engineering, University of Queensland, Brisbane, QLD, Australia \\ Received: 11 May 2020 / Revised: 25 June 2020 / Accepted: 17 September 2020 \\ (C) The author(s) 2020 .
}

\begin{abstract}
Epoxy resin is one of the most widely used thermoset polymers in high-performance composite materials for lightweight applications. However, epoxy has a high coefficient of friction, which limits its tribological applications. In this study, the effect was investigated of different weight fractions of solid lubricant graphene nanoplatelets (GNPs), ranging from 0 to $4.5 \mathrm{wt} \%$, on mechanical and adhesive wear performance of epoxy. Adhesive wear tests covered mild and severe wear regimes. The correlation of tribological and mechanical properties was studied as well. Scanning electron microscopy (SEM) was used to observe the failure mechanisms for both tribological and mechanical samples after each test. The results revealed that the addition of GNPs to the epoxy improved its stiffness and hardness but reduced its fracture strength and toughness. Adhesive wear performance exhibited high efficiency with GNP additions and showed reductions in the specific wear rate, the coefficient of friction, and the induced interface temperature by $76 \%, 37 \%$, and $22 \%$, respectively. A fatigue wear mechanism was predominant as the applied load increased. Most importantly, severe wear signs occurred when the interface temperature reached the heat distortion temperature of the epoxy. The tribological, and mechanical properties showed only a weak correlation to each other. The addition of GNPs to epoxy by less than $4.5 \mathrm{wt} \%$ was highly efficient to improve the wear performance while maintaining the fracture strength and toughness. Fourier transform infrared spectroscopy (FTIR) analysis shows no chemical interaction between the epoxy matrix with GNPs, which implies its physical interaction.
\end{abstract}

Keywords: graphene nanoplatelets; epoxy; adhesive wear; solid lubricants

\section{Introduction}

Polymeric composites continue entering into broader industries because of their high strength-to-weight ratio. In tribological applications, there is an increasing trend to replace the bearings, gears, and bushings that are based on metals such as copper and bronze by polymeric composite materials [1-3]. In lightweight applications such as robotic, electronic, and electrical systems, the tribological components such as bearings and bushings are entirely made from polymers, due to their high strength/weight ratio [4]. In tribological applications, several polymers are used for this purpose such as epoxy, polytetrafluoroethylene (PTFE), ultra-high molecular weight polyethylene (UHMWPE), and polyether ether ketone (PEEK) [5].

Epoxy is a common thermoset polymer having numerous advantages including, but not limited to

* Corresponding author: K. Y. EAYAL AWWAD, E-mail: Khaled.EayalAwwad@usq.edu.au 
its low cost, the high value of its weight to strength ratio, its durability under low and high temperatures, its anti-corrosive nature, and its good thermal stability with low shrinkage. Epoxy resin and its composites are used in many applications such as adhesives, brake materials in automotive, biocompatible implants, and aviation parts [3, 5]. Among thermoset polymers, neat epoxy resin has low thermal conductivity and a high coefficient of friction [6], which has limited its tribological applications. However, adding some suitable fillers can improve these properties, which will promote its usage in tribological applications.

Extensively investigated previously, the use of nanofillers has shown a potential improvement of various characteristics of polymers, including their mechanical, thermal, and tribological properties [7, 8]. In a complex process like wear, the main challenge is how to balance between these properties. Unlike metals, the wear performance of polymers is very sensitive to the operating temperature, i.e., the induced heat at the contact zone during the wear process. In tribological applications of polymers, one main parameter to be considered during the wear process is how the generated heat of the rubbing process affects the tribological components' mechanical and wear performances [9-11]. Interface temperature may deteriorate these components' mechanical properties by reducing the hardness and the stiffness, and it can break the polymer bonds, resulting in a higher wear rate and a higher coefficient of friction (COF) for components $[9,12]$.

From the literature, reducing the COF could be achieved by using various solid lubricant fillers, i.e., molybdenum disulfide, polytetrafluoroethylene, and tungsten disulphide $\left(\mathrm{WS}_{2}\right)[13,14]$. On the other hand, the heat generated in the rubbing process might reduce the efficiency of solid lubricants and thus limit their permissible temperature ranges. For instance, the effect of bonded molybdenum disulfide $\left(\mathrm{MoS}_{2}\right)$ on the tribological properties of novolac epoxy was studied by Ye et al. [15]. Test results showed significant improvement in fretting wear behaviours, indicated by the low COF and low wear rate. However, the temperature has to be controlled by the short sliding of distance to avoid the oxidation of $\mathrm{MoS}_{2}$ which can reduce the efficiency of its lubrication properties. PTFE as a solid lubricant material showed high wear performance by reducing the polymers' COFs [13]. However, PTFE has a low thermal conductivity at $0.2-0.3 \mathrm{~W} /(\mathrm{m} \cdot \mathrm{K})[16]$, similar to the value of epoxy, which is $0.2 \mathrm{~W} /(\mathrm{m} \cdot \mathrm{K})$ [6]. Therefore, adding PTFE provides no benefit to improve the thermal properties of polymers. For this reason, the lubrication efficiency of PTFE is restricted to below the specific polymer's temperatures such as its heat distortion temperature (HDT).

For tribological applications, under a combination of thermo-mechanical stresses, it is desirable to enhance the frictional behaviour as well as the thermal conductivity of the polymer. Because of their high thermal conductivity and lubrication properties, nanocarbon materials like graphite and graphene attract more research in this field of applications. These materials have the potential for the tribological improvement of polymers, acting as a solid lubricant and improving the thermal conductivity of polymer composites $[8,13$, 17]. Due to their intrinsic mechanical, thermal, and lubrication properties, graphene nanoplatelets (GNPs) are recommended as a solid lubricant to improve the tribological performance of epoxy. GNPs have a high stiffness of 1,000 GPa as well as a high tensile strength of around 130 GPa [8, 13]. The in-plane thermal conductivity of GNPs is $5,000 \mathrm{~W} /(\mathrm{m} \cdot \mathrm{K})$ [6], which is 25,000 times that of epoxy. The effect of graphene fillers has been investigated in terms of improving the mechanical and tribological properties of polymers, such as PEEK [8] and nylon 66 [13]. These works have suggested promising results. The literature, however, offers few studies addressing the impact of GNPs' addition on dry adhesive wear performance and the mechanical properties of epoxy, nor is there much research on the correlation between both behaviours.

In light of the above, the current study aims to investigate the effect of GNPs as a solid lubricant on both the adhesive wear performance and the 
mechanical properties of epoxy-based composites. Different weight fractions of GNPs were added into the epoxy resin. The effect of induced interface temperature during the wear test on the wear performance of epoxy, with and without the presence of GNPs, was investigated. We assessed the optimal percentage of GNPs in terms of a balance between epoxy composites' mechanical and tribological properties. Furthermore, the effects were explored of the addition of GNPs on the microstructure of epoxy and on its efficiency in dissipating the heat generated due to rubbing.

\section{Materials and experimental procedures}

\subsection{Materials}

Epoxy resin (R246TX) with the curing hardener (H160) (4:1 weight ratio), an HDT of $65{ }^{\circ} \mathrm{C}$, and a density of $1.07 \mathrm{~g} / \mathrm{cm}^{3}$ at $25{ }^{\circ} \mathrm{C}$ was selected for the current study. The resin system was supplied by ATL Composites Pty. Ltd., Australia. The graphene nanoplatelets (GNPs) Grade C particles with an average surface area of $300 \mathrm{~m}^{2} / \mathrm{g}$ were supplied by Sigma-Aldrich Pty. Ltd., Australia. Epoxy composites based on different concentrations of GNPs were prepared and labelled as epoxy-GNPs- $x$, where $x$ is the GNPs' weight percentage.

\subsection{Sample preparation}

Due to the huge surface area of $300 \mathrm{~m}^{2} / \mathrm{g}$ of GNPs, and to avoid the high possibility of aggregation and/or agglomeration during the mixing process, only small amounts of GNPs were used. Epoxy composites based on different weight fractions of GNPs $(0,1.5,3$, and $4.5 \mathrm{wt} \%)$ were fabricated. To prepare the neat epoxy matrix, the resin epoxy and its corresponding hardener were mixed in a ratio of $4: 1$ according to the material specifications. Regarding the epoxy/GNPs composites, the weight fraction of GNPs was gradually added and mixed with an electrical blender (Contempo stick mixer) for $2 \mathrm{~min}$ at $250 \mathrm{rpm}$ to ensure the mixture's homogeneity. The mixing process was conducted at low speed to avoid any excessive heat and trapped air bubbles. To eliminate the air bubbles, the mixture was degassed inside a vacuum oven chamber at a constant vacuum pressure of $70 \mathrm{kPa}$ and $50{ }^{\circ} \mathrm{C}$ for $30 \mathrm{~min}$. Then, the mixture was poured inside the steel mould cavities that had been designed to produce the samples for the tensile and wear tests. The dimensions of the mould for the wear test samples were $58 \mathrm{~mm}$ in length, $20 \mathrm{~mm}$ in width, and $25 \mathrm{~mm}$ in height, designed for a block on ring (BOR) test following the ASTM: G77 standard. For the tensile experiements, dog-bone samples were prepared in dimensions of $190 \mathrm{~mm}$ in total length, with $80 \mathrm{~mm}$ in the length of the narrow section, $20 \mathrm{~mm}$ in overall width, with $10 \mathrm{~mm}$ in width at the narrow section, and $8 \mathrm{~mm}$ in thickness according to ASTM D638-99. The moulded samples were kept under atmospheric conditions at $25{ }^{\circ} \mathrm{C}$ for $24 \mathrm{~h}$ for the self-curing process. The composites were post-cured in the oven for $4 \mathrm{~h}$ at $100{ }^{\circ} \mathrm{C}$, based on the material preparation specifications, to improve the HDT of the epoxy and its composites. Figure 1 summarises the sample preparation method for the epoxy composites.

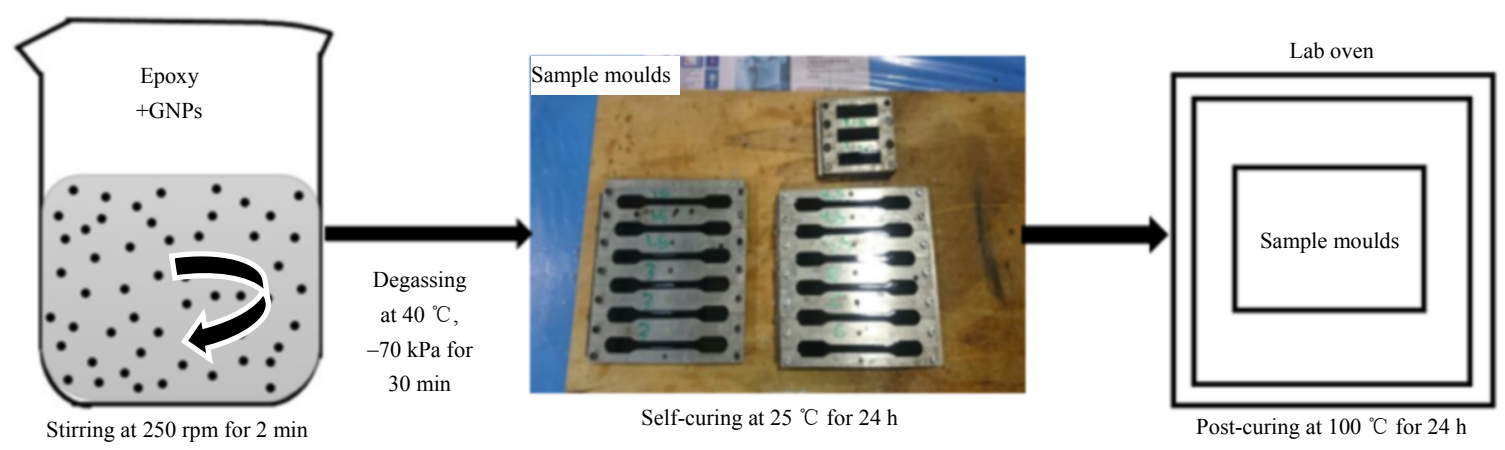

Fig. 1 Schematic illustration for the sample preparation of epoxy-GNP composites. 


\subsection{Testing procedure}

\subsubsection{Mechanical properties}

Tensile tests were conducted on an MTS 810 TestStar material testing machine with $10 \mathrm{kN}$ of load capacity. The loading rate was maintained at $1 \mathrm{~mm} / \mathrm{min}$ in conformity with ASTM D638-99. The tensile strength, fracture strain, stiffness, and toughness were obtained from the engineering stress-strain curves. The hardness was measured by using a Durometer-D following ASTM D2240. For repeatability and reproducibility of the results, at least 3 tensile samples were tested for each composite, and for the hardness test, three readings were taken for each composite and the average value was calculated.

\subsubsection{Tribological properties}

For the majority of tribological components, the variable contact area is in tangential traction with a steel type counterface [18]. Accordingly, to accurately characterise the wear mechanism of this type of component, a BOR machine was selected in this study. In tribological applications such as bearings, the steel counterface such as mild steel and stainless steel rotates against polymeric composite materials. Using a steel counterface is recommended due to its high relative thermal conductivity of $16 \mathrm{~W} /(\mathrm{m} \cdot \mathrm{K})$ [19] compared with polymer materials. The higher conductivity accelerates the dissipation of generated heat at the contact wear zone.

The effect of GNPs on the adhesive wear performance of epoxy was investigated by using the BOR machine following ASTM G77. The stainless steel counterface, AISI 304 and $1250 \mathrm{HB}$, was tangentially rotated with respect to the wear sample as illustrated in Fig. 2. The tests were conducted in a dry contact condition $\left(22{ }^{\circ} \mathrm{C}\right.$, relative humidity $40 \%-50 \%$ ). The sliding velocity was maintained at $2 \mathrm{~m} / \mathrm{s}$, with the applied loads of $15,30,45$, and $60 \mathrm{~N}$. The maximum and minimum contact pressures $(P)$ at the steady state region were obtained through finite element modelling, and these ranged between 0.35 and $0.53 \mathrm{MPa}$

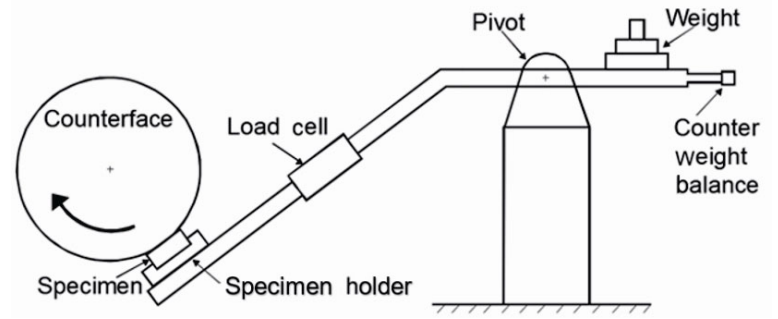

Fig. 2 Schematic illustration of BOR machine.

corresponding to the applied loads of 15 and $60 \mathrm{~N}$, respectively. These testing parameters were selected to simulate mild and severe sliding wear of bearing applications where the pressure velocity product (PV) values fluctuated between 0.33 and $3.9 \mathrm{MPa} \cdot \mathrm{m} / \mathrm{s}[20,21]$. The sliding distance was $6 \mathrm{~km}$, allowing the system to reach the steady state region of the wear process.

Before each test, both surfaces of the steel counterface and the surface of the wear samples were polished by using 1,000- and 1,200-grit grinding papers and then cleaned by acetone. The surface roughness of the counterface, as well as the wear samples, were controlled to be less than $0.2 \mu \mathrm{m}(R a)$. The friction force of the rubbing process between the counterface and the wear samples was continuously recorded through a Mettler Toledo load cell with $0.0098 \mathrm{~N}$ accuracy. The friction coefficient was calculated by dividing the friction force by the applied force. In order to calculate the specific wear rate $\left(W_{\mathrm{s}}\right)$ of the epoxy and its composites, the worn surface of the samples was carefully scrubbed by soft tissue paper soaked in acetone to remove any suspended particles on the worn surface. After that, an air dryer was used to remove any remaining moisture. The mass loss for each sample was measured after every kilometre of the sliding distance, up to a total of $6 \mathrm{~km}$, by using a mass scale with an accuracy of $1.0 \times 10^{-5} \mathrm{~g}$. Therefore, $W_{\mathrm{s}}$ was calculated based on the following equation:

$$
W_{s}=\frac{\Delta V}{L \cdot F_{\mathrm{N}}}\left(\mathrm{mm}^{3} /(\mathrm{N} \cdot \mathrm{mm})\right)
$$

where $\Delta V$ is the worn volume $\left(\mathrm{mm}^{3}\right), L$ is the sliding distance $(\mathrm{m})$, and $F_{\mathrm{N}}$ is the normal load $(\mathrm{N})$. For repeatability of the adhesive wear test, at least 3 samples were tested at the same wear 
conditions for each composite and the average values were plotted.

The surface roughness of the wear track and the worn surfaces were measured before and after each test by using an MarSurf M 400 profilometer. The interface temperature at the rubbing process was measured by a Testo 876 thermal camera.

\subsubsection{Fourier transform infrared spectroscopy (FTIR) spectroscopy, Raman spectroscopy, and X-ray diffraction (XRD)}

FTIR was performed using a Nicolet iS50 FT-IR spectrometer to study the chemical interaction between the GNPs and epoxy matrix. Neat epoxy and its composite were milled and prepared as powder while the GNPs was already in a powder form. The FT-IR spectra of the powder samples were recorded using a Nicolet iS50-ATR module at 32 scans with a resolution of $4 \mathrm{~cm}^{-1}$ and within the wavenumber range of 2,000-500 $\mathrm{cm}^{-1}$.

Raman spectra of the graphene, epoxy, and epoxy-graphene composites were collected using a Renishaw inVia InSpect dispersive Raman spectrometer. Similar to FTIR analysis, epoxy and its composites were milled and prepared as powder while the GNPs was already in a powder form. The 50× objective was used along with the $785 \mathrm{~nm}$ laser. For the epoxy and epoxy graphene samples the laser power was set at $5 \%(1 \mathrm{~mW})$ and for the graphene powder a laser power of $1 \%$ $(0.2 \mathrm{~mW})$ was used. Spectra were collected using the extended scan function with an acquisition time of $10 \mathrm{~s}$ to give spectra between 99 and $3,200 \mathrm{~cm}^{-1}$.

XRD patterns of GNPs, neat epoxy, and its composite were obtained using a Leybold-554 800 diffractometer equipped with a $\mathrm{Cu} \mathrm{K} \alpha \mathrm{X}$-ray tube and end-window counter detector with cable for $\alpha$, $\beta, \gamma$, and X-rays. Data were recorded of $2 \theta$ ranging between $10^{\circ}$ and $40^{\circ}$ with a scan step of $2 \theta=0.2^{\circ}$ for $30 \mathrm{~min}$.

\subsubsection{Scanning electron microscopy (SEM) analysis}

The worn surfaces of the wear samples, as well as the fractured surfaces of the tensile specimens, were investigated by using a scanning electron microscope JEOL JCM-6000 Benchtop, at the acceleration voltage of $5 \mathrm{kV}$. Before the SEM observations, the studied surfaces were coated with a thin layer of gold to enhance their conductivity by using an ion sputtering device (JEOL Smart Coater).

\section{Results and discussion}

\subsection{FTIR spectroscopy, Raman spectroscopy, and XRD measurments}

FTIR spectral measurements were used to determine the functional groups present in the materials, and interactions between GNPs and epoxy molecules. FTIR spectra of graphene nanoplatelets, pure epoxy, and epoxy-GNPs composite are shown in Fig. 3. In the figure, infrared (IR) spectra of GNPs show small peaks at around 1,550 and $1,650 \mathrm{~cm}^{-1}$, which are corresponding to a $\mathrm{C}=\mathrm{O}$ stretching vibration of the carboxylic group and the contribution of skeletal graphitic carbon atoms. IR spectra of pure epoxy reveal that it has main peaks at: (i) $1,604,1,505$, and $1,454 \mathrm{~cm}^{-1}$, which are assigned to a $\mathrm{C}-\mathrm{C}$ stretching vibration of aromatic rings; (ii) $1,298 \mathrm{~cm}^{-1}$ assigned to asymmetrical deformation of $-\mathrm{CH}_{2}$ groups; (iii) $1,253 \mathrm{~cm}^{-1}$ assigned to asymmetrical aromatic $\mathrm{C}-\mathrm{O}$ stretching; (iv) $1,224 \mathrm{~cm}^{-1}$ assigned to asymmetrical aliphatic C-O stretching; (v) $1,032 \mathrm{~cm}^{-1}$ assigned to symmetrical aromatic C-O stretching; (vi) $826 \mathrm{~cm}^{-1}$ assigned to $-\mathrm{CH}$ out of plane deformation in aromatic and epoxide ring vibrations; and (vii) $593 \mathrm{~cm}^{-1}$ assigned to the frequency of aromatic groups.

These results reveal the polymerization of the monomer with the hardener and the successful formation of solid epoxy resin. It was found that the IR spectrum of the epoxy composite prepared with less content of GNPs is similar to that of neat epoxy, except the main bands observed in the composites were shifted to wave numbers by $5-15 \mathrm{~cm}^{-1}$, indicating the formation of composites through physical or van der Waals interactions between epoxy molecules and GNPs. 


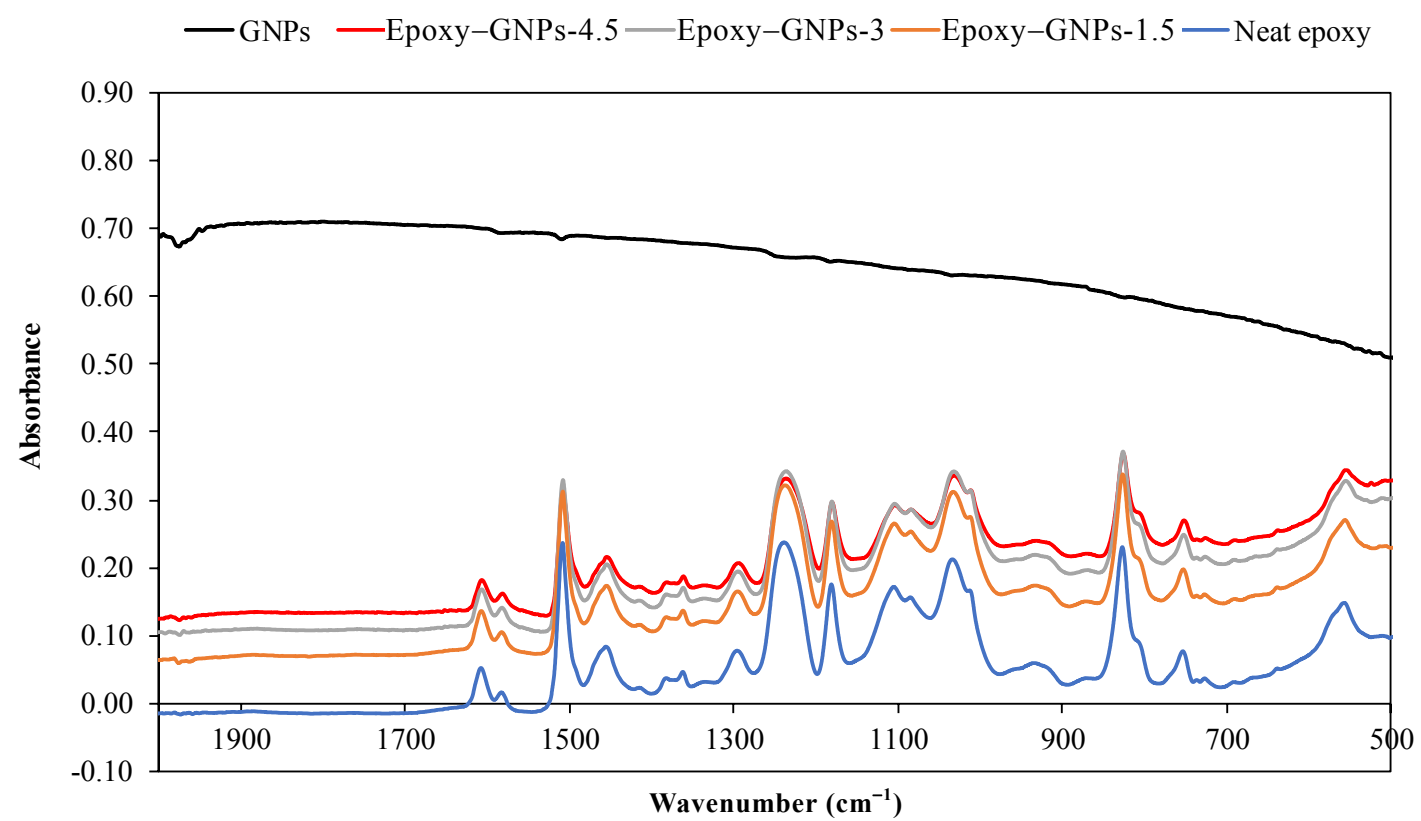

Fig. 3 FTIR spectra of GNPs, neat epoxy, and epoxy-GNPs- $x$ composites; wavenumber of 500-2,000 $\mathrm{cm}^{-1}$.

Raman spectra of GNPs, neat epoxy, and GNPs/ epoxy composites prepared with different weight percetage of GNPs are presented in Fig. 4(a). Neat epoxy has peaks at $653,795,1,130,1,190,1,254$, $1,300,1,430,1,480,1,580,2,490$, and $2,880 \mathrm{~cm}^{-1}$, which are corresponds to functional groups of cured epoxy resin. GNPs show the typical disorder-induced $\mathrm{D}$ band at around $1,310 \mathrm{~cm}^{-1}$, the tangential mode $\mathrm{G}$ band at around $1,580 \mathrm{~cm}^{-1}$, and a minor peak at $2,630 \mathrm{~cm}^{-1}$ which belong to $G^{\prime}$ band. After the formation of composites with the combination of epoxy and GNPs, composites showed both Raman peaks of neat epoxy and GNPs. However, D and G bands of GNPs in Raman spectra of composites are overlapped with peaks of neat epoxy, with an increasing intensity (a)

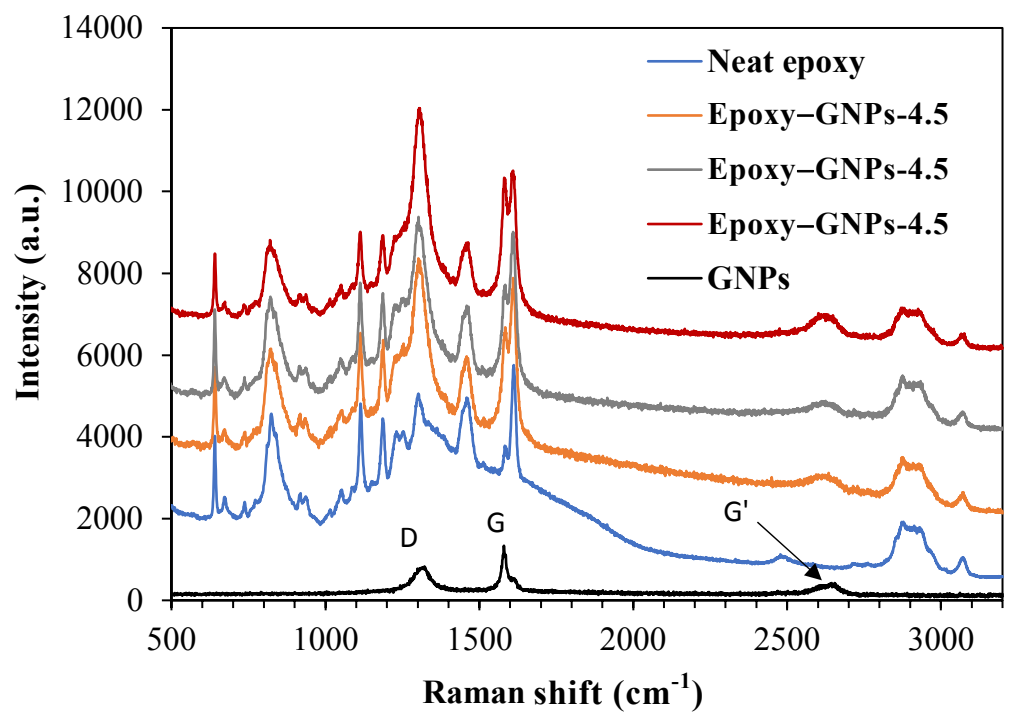

(b)

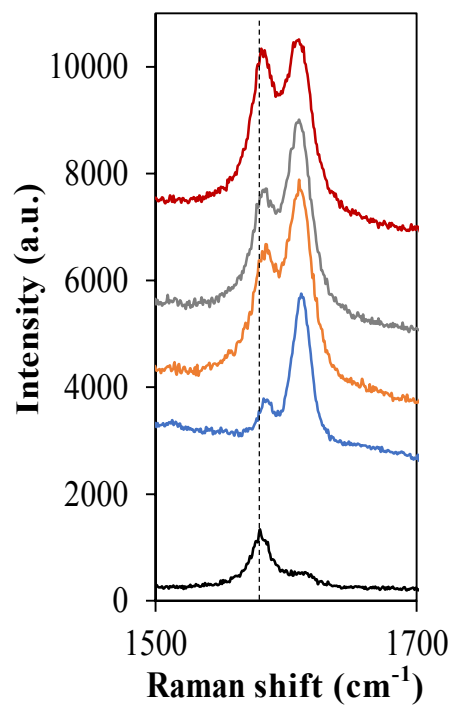

Fig. 4 Raman spectra of neat epoxy, GNP powder, and epoxy-GNPs- $x$ composites: (a) baseline corrected spectra and (b) insight of the $\mathrm{C}=\mathrm{C}$ and $\mathrm{C}=\mathrm{O}$ stretching region of epoxy. 
for increasing GNPs amounts. In addition, the intensity of $G$ and $G^{\prime}$ bands of GNPs in the composites is increased as well as shifted to lower wavenumbers with increasing amount of GNPs in the composites, as shown in Fig. 4(b). Therefore, the $G$ and $G^{\prime}$ lines can be used as averification of the composite composition.

XRD studies were conducted to determine the differences in the crystalline behaviour of materials. The XRD patterns of graphene nanoplatelets, pure epoxy, and epoxy-GNPs-4.5 composite are presented in Fig. 5. Figure 5 shows that graphene nanoplatelets have a diffraction peak at about $26.7^{\circ}$, which is assigned to the ordered structure of graphitic carbon and indicates good crystallinity. The diffraction pattern of pure epoxy clearly shows that it is completely amorphous. The diffraction pattern of epoxy composites prepared with less content of GNPs has similar structural features to that of pure epoxy, except a small broad pattern appears in the range of $13^{\circ}-18^{\circ}$, suggesting that the completely amorphous nature of pure epoxy was changed to partial semicrystalline behaviour.

\subsection{Mechanical characteristics}

The mechanical properties of epoxy and its composites, including the tensile strength, stiffness, fracture strain, toughness, and hardness were evaluated. Figure 6 shows the tensile strength and modulus of elasticity for the different epoxy composites incorporated with the different weight percentages of graphene nanoplatelets (GNPs).

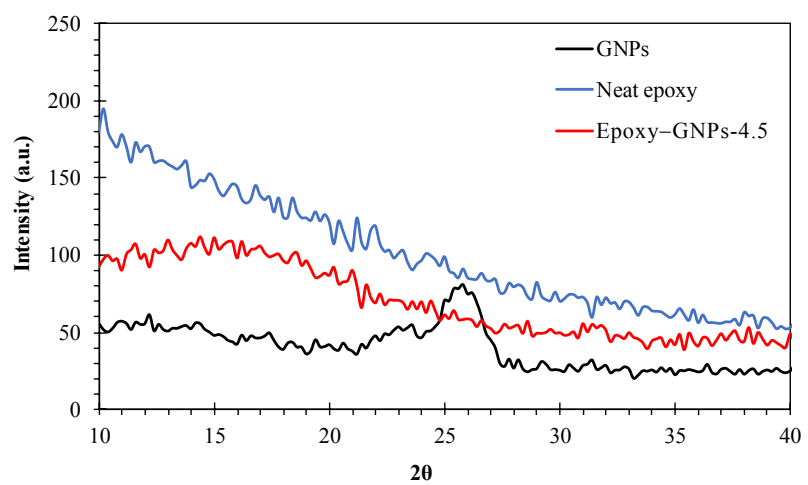

Fig. 5 XRD patterns of GNPs, neat epoxy, and epoxyGNPs-4.5 composite.
The mechanical properties of neat epoxy are in agreement with published studies: 58-94 MPa for the tensile strength and $0.6-2.7 \mathrm{GPa}$ for the stiffness [6, 22]. There is a positive correlation between the stiffness and the weight percentage of GNPs, i.e., an increase by $13 \%$ and $15 \%$ for additions of 3 and $4.5 \mathrm{wt} \%$, respectively, of GNPs. In contrast, the tensile strength and the fracture strain did not follow the same trend as the stiffness. Neat epoxy exhibited higher values of strength and fracture strain compared with GNP additions. The addition of GNPs reduced the fracture strength and its associated strain, for instance, the content of $4.5 \mathrm{wt} \%$ of GNPs reduced the tensile strength by $22 \%$ and the fracture strain by $45 \%$, compared with the neat epoxy. Table 1 presents the fracture strain, toughness, and shore D hardness of epoxy and its composites. The incorporation of GNPs into epoxy increased the composite hardness while the fracture strain and toughness were reduced. Similar results have been reported by other authors $[7,8,22]$ concerning the effect of different nanofillers on the strength of the polymer system.

The improvement in the epoxy's stiffness by adding the GNPs is not related to the change in the

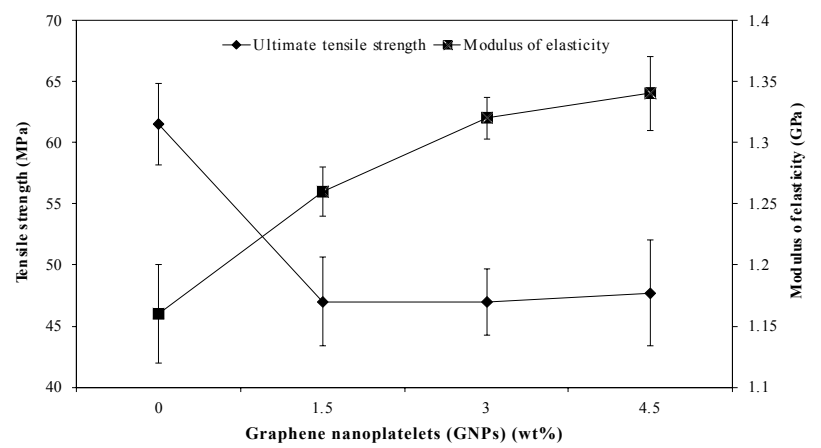

Fig. 6 Effect of GNPs concentration on the stiffness and tensile strength of epoxy.

Table 1 Effects of GNPs addition on the mechanical properties of epoxy.

\begin{tabular}{cccc}
\hline - & $\begin{array}{c}\text { Fracture } \\
\text { strain }(\%)\end{array}$ & $\begin{array}{c}\text { Toughness } \\
\left(\mathrm{MJ} \cdot \mathrm{m}^{3}\right)\end{array}$ & $\begin{array}{c}\text { Shore D } \\
\text { hardness }\end{array}$ \\
\hline Neat epoxy & $7.9 \pm 1.50$ & $2.67 \pm 0.71$ & $79.0 \pm 0.82$ \\
Epoxy-GNPs-1.5 & $4.6 \pm 0.33$ & $0.96 \pm 0.10$ & $82.3 \pm 0.85$ \\
Epoxy-GNPs-3 & $4.4 \pm 0.42$ & $0.92 \pm 0.14$ & $83.3 \pm 0.62$ \\
Epoxy-GNPs-4.5 & $4.3 \pm 0.36$ & $0.93 \pm 0.16$ & $85.0 \pm 0.80$ \\
\hline
\end{tabular}


epoxy's microstructure. The GNP additions are un-functionalized graphene; thus they have no ability to change the density of the cross-linking structure of epoxy by raising or decreasing the fraction of the network phase [23]. Instead, this improvement could be primarily attributed to the role of the mixture by taking into account interfacial efficiency. The GNPs' stiffness is around 1,000 GPa [6]; also the nanofillers provide a huge surface area per unit mass, $300 \mathrm{~m}^{2} / \mathrm{g}$ in this study. This also explains the tendency to increase hardness with an increase of the GNPs' weight fraction. Similar conclusions have been reported for other polymeric systems, for instance, UHMWPE [17], and PEEK [8].

The primary reason behind the reduction in the tensile strength is related to the aggregation and the agglomeration of the nanofillers, which caused a low interaction with the polymer matrix, thus producing stress raisers inside the matrix. The aggregation of GNPs and their weak interfacial adhesion with the matrix can explain this reduction in the strength. GNPs tend to aggregate due to the van der Waals forces and $\pi-\pi$ interactions between graphene layers, which usually make the dispersion process inside the polymer matrices a challenge $[24,25]$. Also, the exothermic heat flow produced during the stirring process supports the agglomeration of GNPs by reducing the epoxy matrix's viscosity. Moreover, the crystal structure of GNPs' fillers inside the epoxy network structure might produce embrittlement phases and thus reduce the polymers' fracture strength and strain [7]. Brittleness leads to restriction of the molecular chain movement inside the epoxy matrix, which is indicated by a high reduction in fracture strain [23].

The interactions between the GNPs and the matrix have a significant effect on the fracture toughness [23]. As mentioned above, there are no chemical bonds between the GNPs and epoxy matrix to affect the epoxy matrix's properties. However, all epoxy-GNP composites exhibited lower toughness compared with neat epoxy. This is in agreement with the literature, as reviewed by Ref. [26], which found that the toughness of epoxy dropped when the weight fraction of graphene exceeds $1 \mathrm{wt} \%$. Prior research studies indicate that functionalized graphene exhibits a lower reduction in the toughness of polymers compared with un-functionlized graphene [23, 27]. Further evidence of the fracture mechanisms is presented in Fig. 7, which shows the SEM micrographs of the fractured surfaces after the tensile testing. In the neat epoxy (Fig. 7(a)), the fractured surface has a cleavage failure associated with high shear resistance as indicated by stretching, which is typical for epoxy and demonstrated by its highest fracture strain and toughness.

The fractured surface of neat epoxy has more stretching marks indicated by the river-like pattern (Fig. 7(a)), while graphene addition induced more brittle behaviours at the fracture surfaces (Figs. $7(b)-7(d))$. The squamous-like pattern indicates a high degree of brittle behaviour for the matrix composite. Where there is a higher content of GNPs, the squamous-like morphology becomes more visible due to the increase of graphene fraction, as shown in Figs. 7(c) and 7(d). All composites show no evidence of manufacturing defects such as voids and bubbles; this was achieved by the controlled mixing and degassing during the fabrication.

\subsection{Tribological behaviour}

To assess the wear performance of the epoxy-GNP composites, dry adhesive wear tests were carried out by using the BOR machine. The effects of GNPs on the specific wear rate, COF, and interface temperature are evaluated and discussed in this section. The worn surfaces were observed using SEM to identify the wear mechanisms.

\subsubsection{Wear performance}

The wear behaviour of the epoxy-GNP composites was evaluated considering the different weight percentages of GNPs. Figure 8 clearly shows the positive influence of GNPs on reducing the wear rate of epoxy at $30 \mathrm{~N}$ of applied load and after $6 \mathrm{~km}$ of sliding distance. The average specific wear rate of the neat epoxy was about $(1.04 \pm 0.13) \times$ 

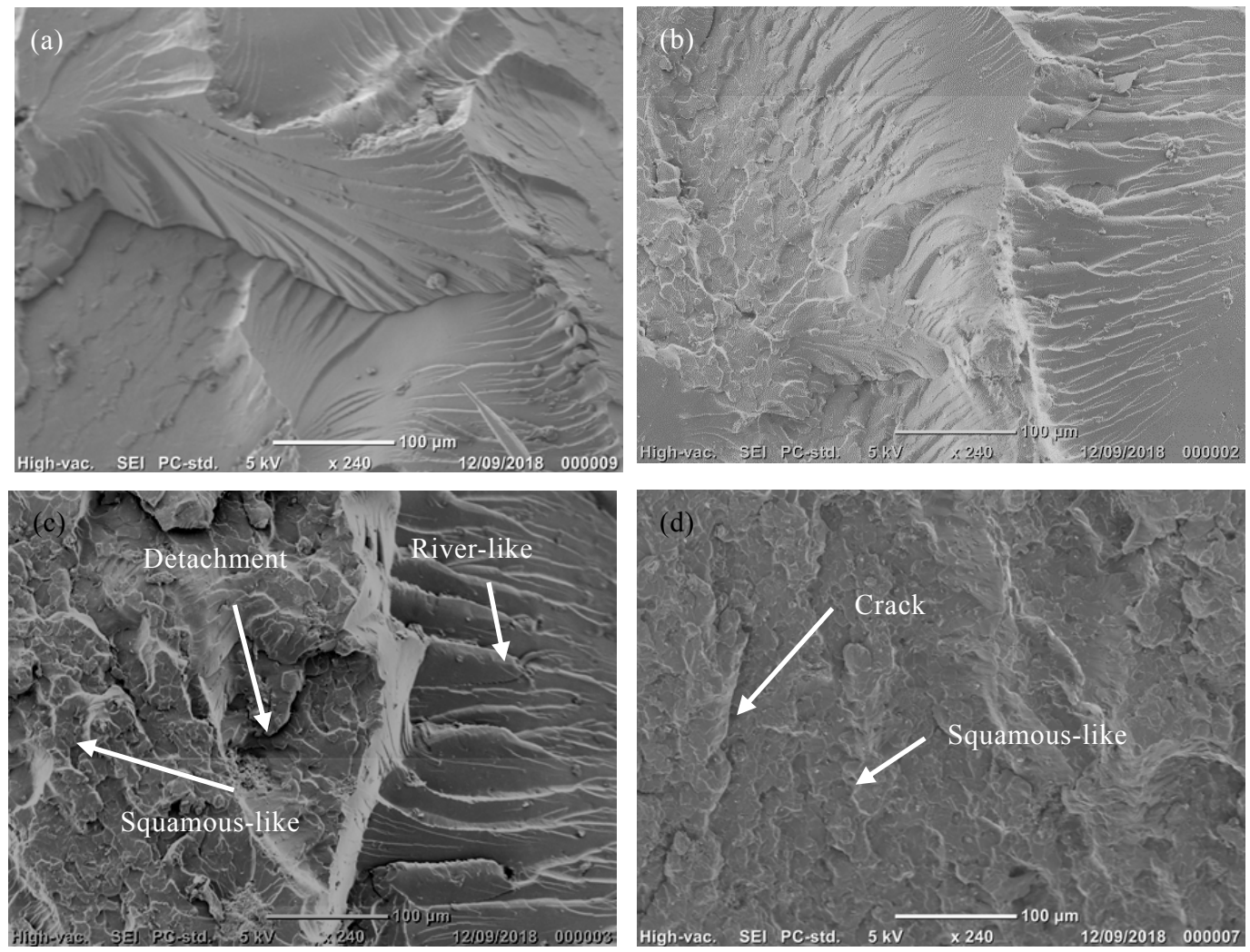

Fig. 7 SEM micrographs of neat epoxy and epoxy-GNP composites after tensile testing: (a) neat epoxy, (b) epoxy-GNPs-1.5, (c) epoxy-GNPs-3, and (d) epoxy-GNPs-4.5.

$10^{-5} \mathrm{~mm}^{3} /(\mathrm{N} \cdot \mathrm{m})$, which is in good agreement with the value of $1.6 \times 10^{-5} \mathrm{~mm}^{3} /(\mathrm{N} \cdot \mathrm{m})$ obtained by Shalwan and Yousif [22] using a BOR machine at $2.8 \mathrm{~m} / \mathrm{s}$ and after $5.5 \mathrm{~km}$ with similar contact conditions. A higher concentration of GNPs leads to a lower wear rate at this wear condition. For instance, a $4.5 \mathrm{wt} \%$ of GNPs reduced the specific wear rate by $76 \%$ compared with the neat epoxy. This improvement is attributed to the ability of

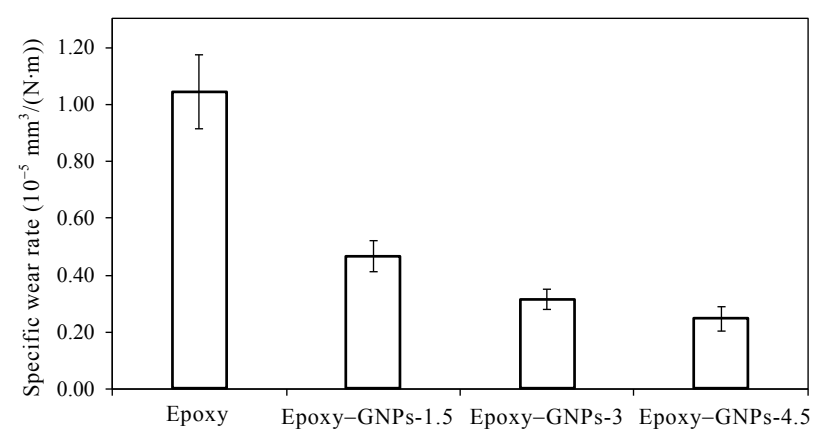

Fig. 8 Average specific wear rate of epoxy-GNP composites, at $30 \mathrm{~N}$ of applied loads and after $6 \mathrm{~km}$ of sliding distance.
GNPs to produce a stable transfer film. The created transfer film acts as a thin coating layer during the rubbing process between the steel counterface and the worn surface, and thus protects the worn surface from further material removal.

The effect of the applied load on the wear rate of the composites is presented in Fig. 9. For all composites, $30 \mathrm{~N}$ of applied load showed a good

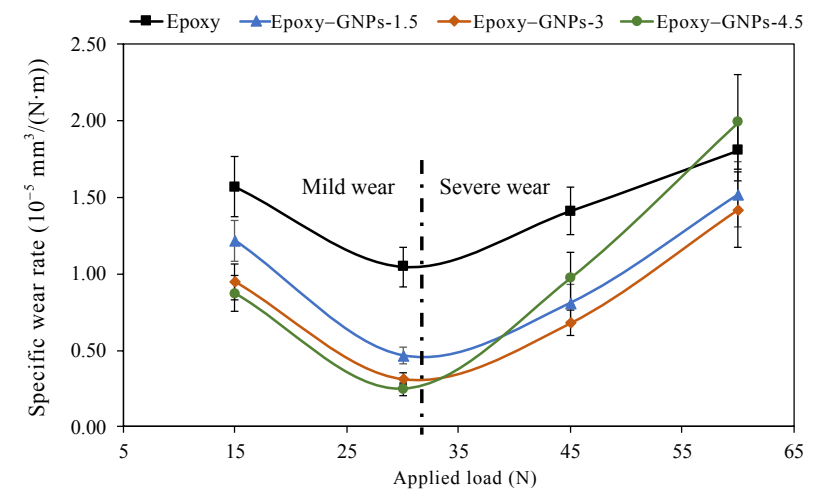

Fig. 9 Influence of applied load on the specific wear rate of epoxy-GNP composites. 
wear resistance, with the lowest values for the specific wear rates. There is increasing mass loss with the increase of applied load. An applied load above $30 \mathrm{~N}$ shows the transition from mild wear to severe wear. A similar observation has been reported through other published works on epoxy composites [28]. A possible reason for the lower wear rate of $30 \mathrm{~N}$ when compared with $15 \mathrm{~N}$ is that the higher induced interface temperature at $30 \mathrm{~N}$ leads to the formation of a thin viscoelastic layer. This thin layer helps to avoid the initiation of brittle cracking in the matrix under the fatigue loads. This behaviour was also reported by Akpan et al. [29] for acrylic resin. However, higher applied loads of 45 and $60 \mathrm{~N}$ lead to induced high thermo-mechanical stress at the wear zone. The same trend was reported for wood/acrylic resin [24] and graphite/cotton reinforced polyester [30]. Moreover, it was observed that the HDT plays a critical role, as once the interface temperature reaches above the HDT of epoxy, $65{ }^{\circ} \mathrm{C}$, and at the same time the sample is subject to high mechanical shear stress, frictional contact causes molecule bonding failure and a loss of load-bearing capacity of the epoxy matrix [12], resulting in further material removal.

The presence of GNPs leads to producing a stable and continuous transfer film. This may explain the improvement in wear resistance under $30 \mathrm{~N}$, compared with neat epoxy, as shown in Fig. 8. However, at a higher load of above $30 \mathrm{~N}$, the specific wear rate was adversely affected by the applied load, especially in the case of the highest GNP content, $4.5 \mathrm{wt} \%$. This behaviour is due to a high reduction in the epoxy's toughness because of the GNP additions, which encourages the fatigue wear mechanism [14]. Higher percentages of fillers above a certain limit would be counterproductive for tribological behaviours due to a drastic decrease in the composite's toughness and strength, especially at high applied loads. The high thermo-mechanical loading at $60 \mathrm{~N}$ causes more removal of material from the rubbing zone. In the same case of $60 \mathrm{~N}$, neat epoxy suffered from greater thermo-mechanical stress and burnt traces were noticed on the worn surface. However, it is worthwhile mentioning here that the glass transition temperature of neat epoxy is around $100{ }^{\circ} \mathrm{C}$ [31], while the maximum recorded interface temperature was $73.5{ }^{\circ} \mathrm{C}$. This highlights the importance of polymers' specific temperature, the HDT. Further explanations are discussed in the next sections.

\subsubsection{Frictional behaviours}

One of the primary objectives of adding GNPs was to reduce the COF of the epoxy. Frictional behaviours of epoxy are presented in Figs. 10 and 11 , considering the sliding distance, applied loads, and the percentages by weight of GNPs. Figure 10 shows COF curves for neat epoxy and its composites over $6 \mathrm{~km}$ at a mild load of $30 \mathrm{~N}$ (a)

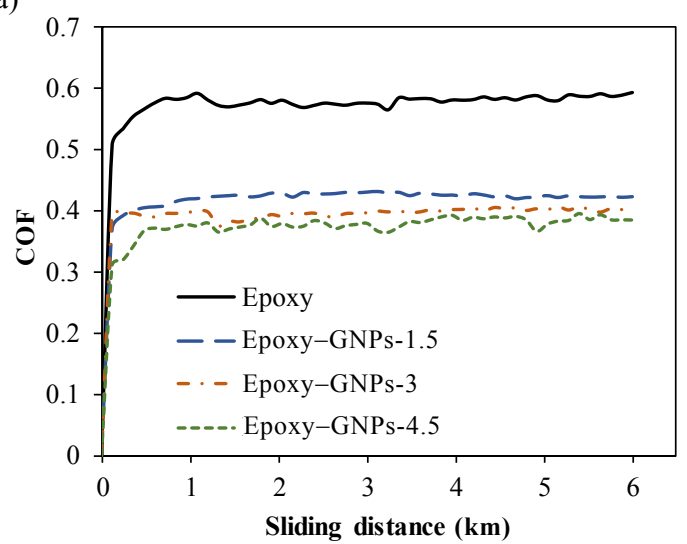

(b)

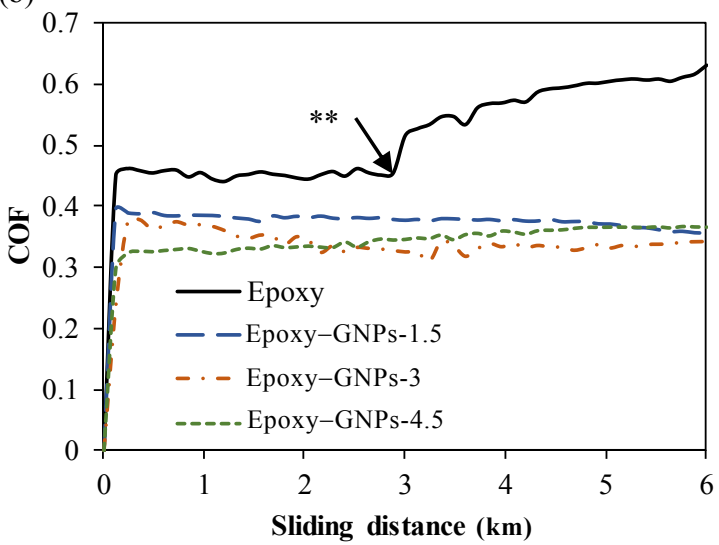

Fig. 10 COF curves of the epoxy-GNP composites over $6 \mathrm{~km}$ of sliding distance at (a) $30 \mathrm{~N}$ and (b) $60 \mathrm{~N}$, where ** indicates that the interface temperature is above the HDT of epoxy. 


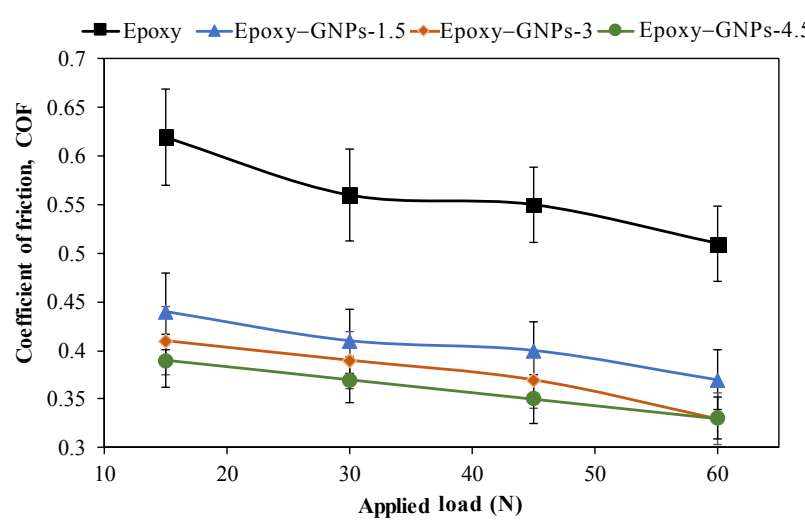

Fig. 11 Influence of different applied loads on the COF of epoxy-GNP composites.

(Fig. 10(a)) and at a high applied load of $60 \mathrm{~N}$ (Fig. 10(b)). For Fig. 10(a), the steady state value of neat epoxy at $30 \mathrm{~N}$ is about $0.56 \pm 0.049$, in good agreement with the value of 0.61 previously obtained by Shalwan and Yousif [22], using a similar tribometer and at nearly similar wear conditions.

Compared with neat epoxy, the COF benefitted by the additions of GNPs under different load conditions. The COF values confirmed the lubrication capability of graphene to reduce the COF of epoxy. This COF reduction is due to the trapped graphene particles that have become detached from the worn surface acting as a lubricant film layer between the worn surface of the specimen and the steel counterface. This behaviour is linked with the lamellar structure of graphene where, for each layer, its atoms are coordinated within a hexagonal unit cell [32]. The bonds between the layers are dominated by the van der Waals forces, which are easily fragmented by the adhesive shear force [33]. The van der Waals energy is inversely proportional to the PV value [1]. The peeled layers develop into a thin lubricant layer that effectively reduces the COF.

The current study shows that the transfer film depends on the content of the GNPs, the applied load, and the interface temperature at the wear zone. All GNPs showed a stable transfer film in the steady state region. It was observed that the more the GNP content, the more stable the film. A similar phenomenon has been reported for other types of solid lubricants such as polytetrafluoroethylene [34], molybdenum disulfide [15], and graphite [35, 36]. At a high load of $60 \mathrm{~N}$ in (Fig. 10(b)), the COF of the neat epoxy exhibits a drastic increase after $3 \mathrm{~km}$ sliding distance. This sudden change in COF took place when the interface temperature reached the HDT of the neat epoxy, $65{ }^{\circ} \mathrm{C}$. Many researchers have investigated the temprature on the wear and frictional behaviour of polymers. For instance, Tahir et al. [9] studied the effect of the operating temperature on the tribological behaviour of carbon fibre composites with a different epoxy system. They reported that the temperature has a high influence on the COF behaviour, and a drastic increase in the COF was reported at $90{ }^{\circ} \mathrm{C}$, below the glass transition temperature $\left(T_{\mathrm{g}}\right)$ of the epoxy, $100{ }^{\circ} \mathrm{C}$ [31]. HDT is below $T_{g}$; however, it may lead to a molecular bonding failure of the resin matrix, especially under the high mechanical stress of dynamic loads. More evidence is shown in terms of the roughness and SEM micrographs in the following sections.

Compared with the neat epoxy, the presence of GNPs showed much more stable COF curves during the tests under the different applied loads, as shown in Fig. 10(b). This behaviour is mainly attributed to two scenarios. First, GNPs have a high capability of improving the thermal conductivity of polymers [6, 37-39]. For instance, Wang et al. [6] have studied the effect of GNPs with a weight fraction of $0-5 \mathrm{wt} \%$ on the thermal conductivity of epoxy which increased by $115 \%$ compared with neat epoxy, when adding $5 \mathrm{wt} \%$ of GNPs. This improvement in the thermal conductivity led to an increased rate of heat dissipation at the wear zone and thus reduced the thermal stress at the worn surface. Increasing the thermal conductivity leads to a reduction in the interface temperature, as discussed in Section 3.3.3. This effect is one of the distinct properties of graphene and graphite, compared with other solid lubricants. The second scenario is related to the possibility of GNPs to increase $T_{\mathrm{g}}$ as reported by many studies [40-43], thus increasing the range of the working temperature.

The influence of the applied load on the COF is 
presented in Fig. 11. The COF decreased with the increase of the applied load. As the friction force at the interface increases, the film generation between both rubbed surfaces becomes greater with the rise of the interface temperature, which is also affected by the applied load. Similar behaviours have been reported in other polymeric composite systems, such as polyester [44], PTFE [45], and polypropylene [46].

\subsubsection{Interfacial temperature and roughness}

Unlike metals, the wear performance of polymers is highly influenced by heat generation in the contact zone. The primary reason behind this is their low thermal conductivities, which limits their permissible work temperature. Our study shows that GNPs improved the heat dissipation at the contact zone, indicated by lower interface temperatures compared with the neat epoxy, as shown in Fig. 12(a). The accuracy in temperature measurement was about $\pm 3{ }^{\circ} \mathrm{C}$. The temperature increased along with the sliding distance. The maximum recorded interface temperature was $73.5{ }^{\circ} \mathrm{C}$ for the neat epoxy at $60 \mathrm{~N}$ of applied load and after $6 \mathrm{~km}$, exceeding the HDT of neat epoxy, $65{ }^{\circ} \mathrm{C}$. Since the interface temperature exceeded the HDT, there was increased roughness and contact surface area with the softening epoxy, leading to the higher COF, loss of load-bearing capacity and stiffness [12].

(a)

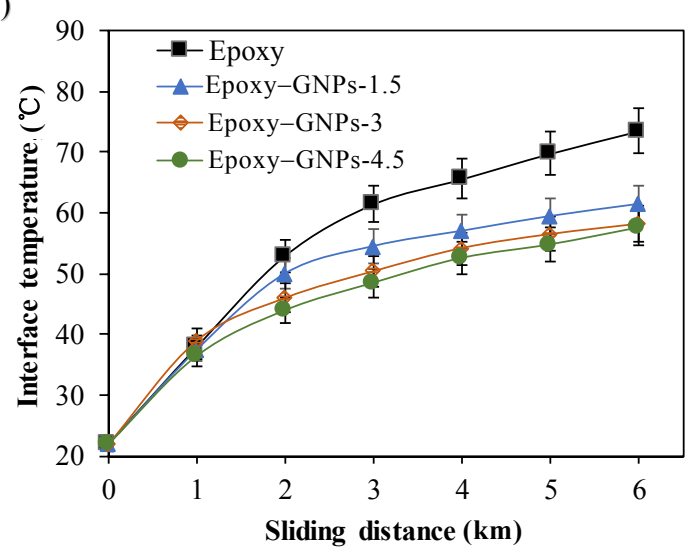

In comparison, the presence of GNPs showed a positive effect on the interface temperature, about a $21.6 \%$ reduction in the temperature with a $4.5 \mathrm{wt} \%$ addition of GNPs. This reduction in the interface temperature is mainly attributed to the expected improvement of the thermal conductivity of epoxy by adding GNPs. In a study by Wang et al. [6], the thermal conductivity increased by about $100 \%$ with $4.5 \mathrm{wt} \%$ of GNPs compared with neat epoxy. In our study, the temperature reduction was slightly lower compared with the expected improvement in the conductivity. One possible reason is that the dissipation of the generated heat depends on the contact area, which is very small on the BOR configuration test. Another possible reason could be the possible aggregation of GNPs inside the epoxy matrix, which causes a reduction in the thermal properties $[6,47]$.

The influence of the applied load on the interface temperature of graphene epoxy composites is presented in Fig. 12(b). The interface temperature is a function of the applied load since the heat generation highly depends on the applied load. The maximum interface temperatures occurred with neat epoxy for all the applied loads, while a $4.5 \mathrm{wt} \%$ achieves the lowest values, under all applied loads.

The rubbing process has a significant impact on the worn surface. Figures 13(a) and 13(b) plot the averages of roughness measurements before and

(b)

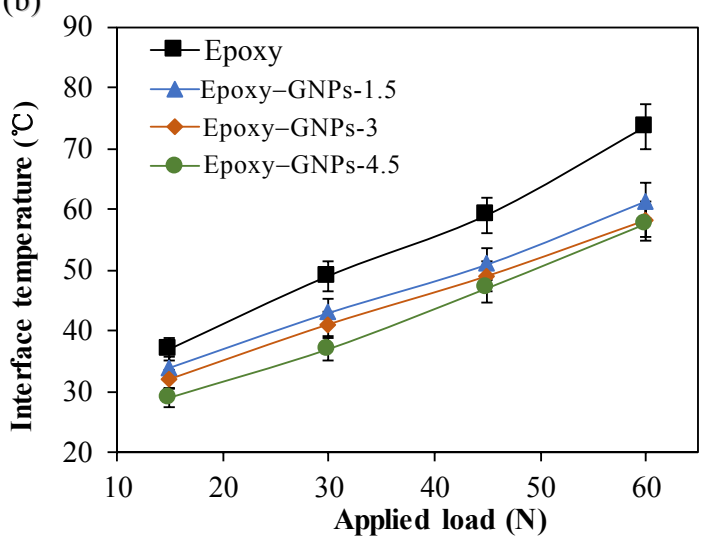

Fig. 12 Interface temperature of epoxy-GNP composites: (a) interface temperature curve versus sliding distance at $60 \mathrm{~N}$ and (b) influence of the applied load on the interface temperature. 
after adhesive wear tests for epoxy and its composites. The results show that the roughness is dependent on the applied load. At the intermediate wear region, i.e., at an applied load of less than $30 \mathrm{~N}$, there was not much difference in the roughness for all materials. However, the roughness varied significantly after the transition from mild to severe wear. In Fig. 13(a), the roughness of the neat epoxy after the adhesive wear tests dramatically increased by about $700 \%$, primarily because the interface temperature of epoxy exceeded the HDT. The loose particles were stacked over the worn surface, which increased the roughness of the worn surface.

Similar trends were observed for the epoxy-GNP composites, although the change in roughness was much less. Figure 13(b) shows the roughness after the adhesive wear for epoxy and its composites after $6 \mathrm{~km}$ and at $45 \mathrm{~N}$. The average roughness of epoxy-GNP composites was lower compared with neat epoxy. However, the transfer films of 1.5 and $3 \mathrm{wt} \%$ of samples reached a stable condition. Moreover, a thicker transfer film was observed in $4.5 \mathrm{wt} \%$ samples at a high applied load.

\subsubsection{Surface SEM analysis}

SEM images of epoxy and its composites after the adhesive wear test against the stainless steel counterface are presented in Figs. 14 and 15. In all cases, these images reveal the deformation and

(a)

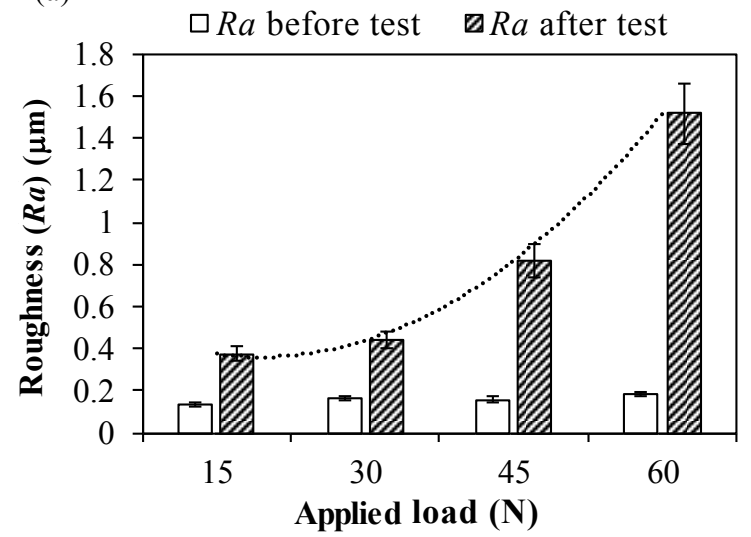

softening processes on the worn surfaces. The effect of the different applied loads on the worn surface of neat epoxy is shown in Fig. 14. At the lower end of the applied load, a large number of cracks and cold rupture signs appear on the worn surface, as shown in Fig. 14(a). The worn surface suffered from softening and deformation with an applied load of $30 \mathrm{~N}$ (see Fig. 14(b)). This deformation is due to an unstable transfer film over the worn surface which protected it from severe wear signs. At a higher applied load, the worn surface of neat epoxy was considerably rougher, and there were loose debris and extensive signs of deformation. For instance, at $45 \mathrm{~N}$, the deformed and loose debris were stacked over the worn surface, due to the significant frictional heat. At $60 \mathrm{~N}$ of applied load (see Fig. 14(d)), there is evidence of fragmentation, peel off, delaminated layers, detachment, and a ruptured surface. These observations are closely related to the high thermo-mechanical stress on the worn surface of the sample. Also, the interface temperature plays an important role in epoxy composites' wear performance. When the interfacial temperature is below neat epoxy's HDT, the frictional contact provides good conditions to create a stable transfer film. Once the interface temperature exceeds this HDT, severe wear signs, as well as a high COF and a high wear rate, will appear.

Many studies have shown that solid lubricant fillers have a significant effect in improving the

(b)

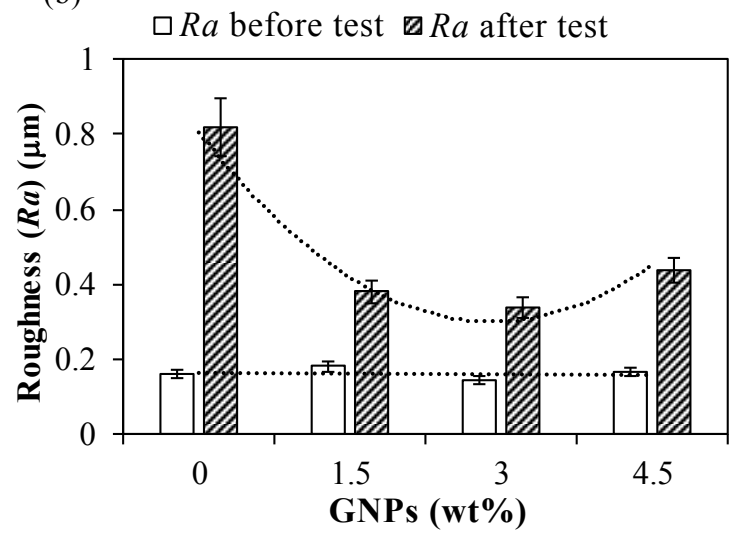

Fig. $13 R a$ roughness values before and after adhesive wear test for (a) neat epoxy at different applied loads and (b) different fractions of GNPs at $45 \mathrm{~N}$ of applied load. 


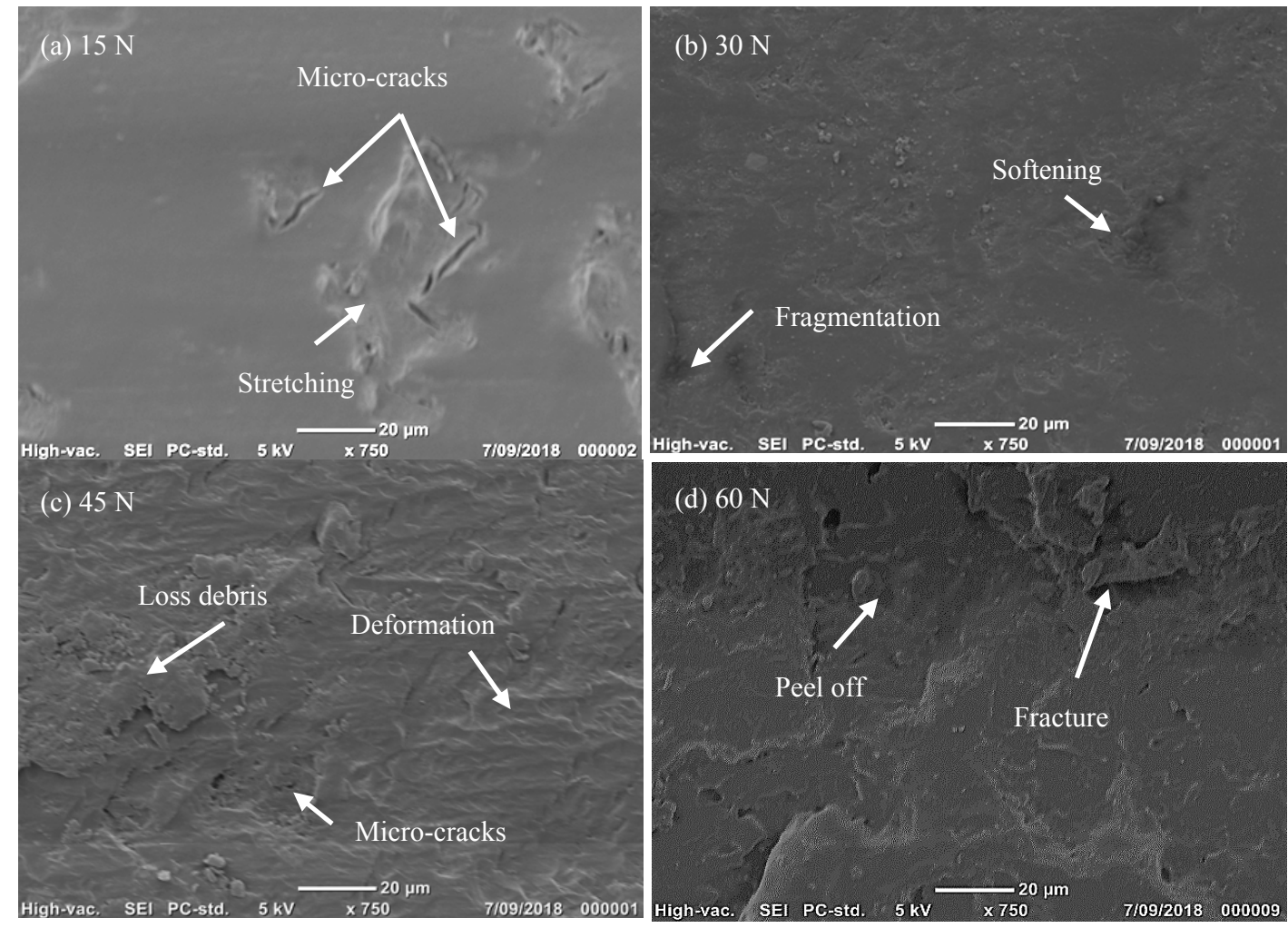

Fig. 14 SEM micrographs of neat epoxy after adhesive wear test by BOR, at different applied loads.

COF and the wear resistance of polymers $[8,13$, 23]. The primary reason for using these materials is their ability to create a stable transfer film during the rubbing process, especially between the steel and polymer contact pairs. Figure 15 shows the SEM images of epoxy-GNPs composites at an applied load of $30 \mathrm{~N}$. Softening and deformation processes on the worn surface of the neat epoxy were noted. Also, there were micro-cracks and fragmentation signs on the surface due to thermo-mechanical stresses at the contact interface. At the same time, the average COF was approximately 0.56. A high rate of mass loss was recorded in this case, confirmed by the relatively high wear rate, as shown in Fig. 8.

Compared with neat epoxy, GNP additions exhibited a noticeable improvement on the worn surfaces. All additions represented a notably stable transfer film that covered the worn surfaces. Figures 16(a) and 16(b) show micrographs of the worn surfaces for both the neat epoxy and epoxy-GNPs- 4.5 composite, after $6 \mathrm{~km}$ of sliding distance. It can be noticed that the worn surface of neat epoxy was suffered from signs of ploughing and microcracks, with no signs of transfer film. On the other hand, clear signs of transfer film were observed in the case of GNP addition, represented by the grey colour as shown in Fig. 16(b). Moreover, For all GNP additions, signs of transfer film were also observed on the steel counterface as shown in Fig. 16(c). This can explain the low values of COF and $W_{\mathrm{s}}$ obtained, compared with neat epoxy. Incorporating GNPs with epoxy changed the wear mechanism due to GNPs' lubrication effect. Also, adding GNPs reduced the interface temperature, which led to decreasing the accompanying thermal stress due to the rubbing process on the worn surface.

\subsection{Tribological and mechanical correlation}

The wear process of polymers is complex, as it depends on various factors, including the type of contact, applied load, sliding velocity, and interface temperature. Limited studies have discussed the correlation between the mechanical and tribological behaviour for polymers. In this 

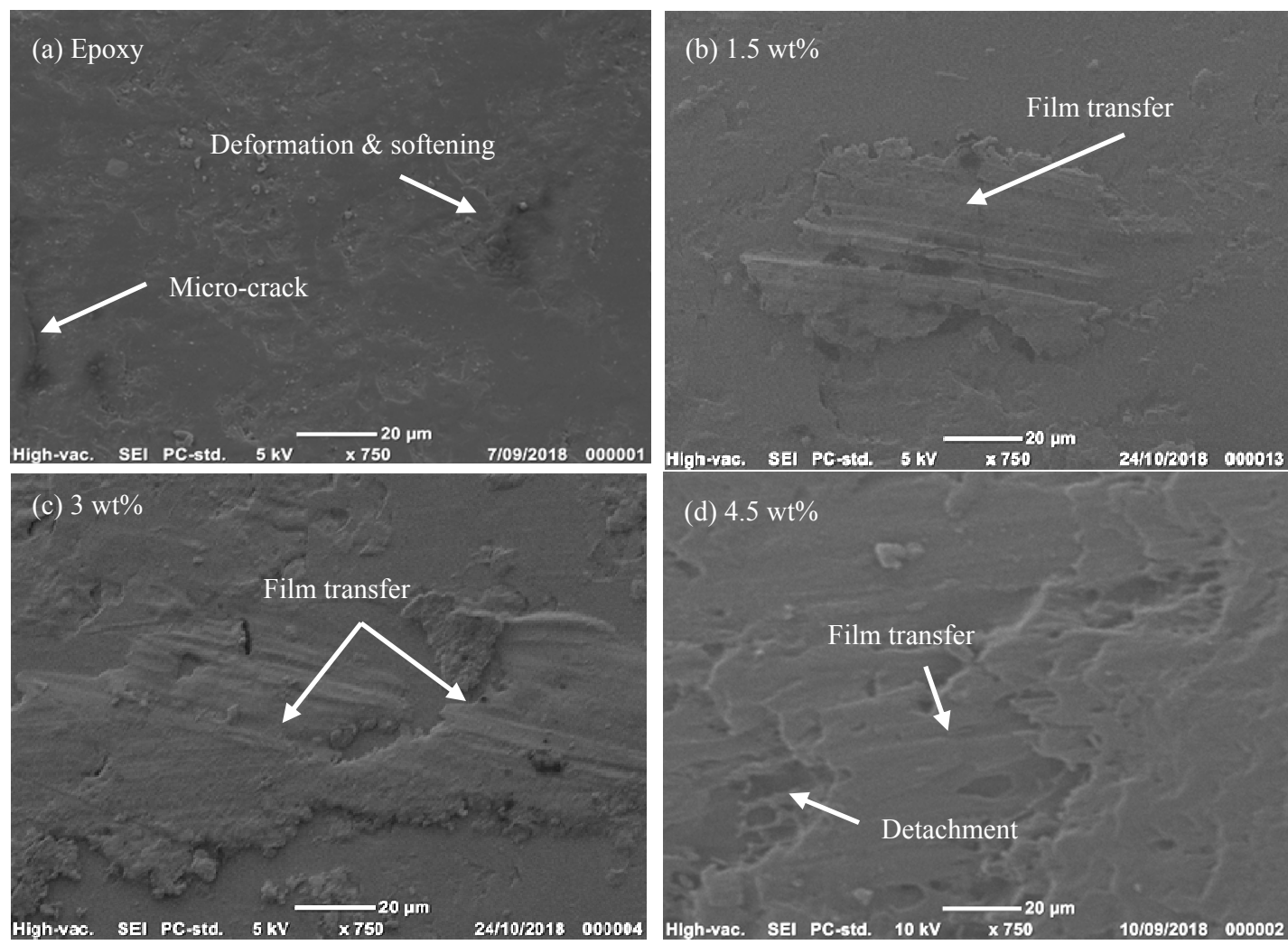

(d) $4.5 \mathrm{wt} \%$

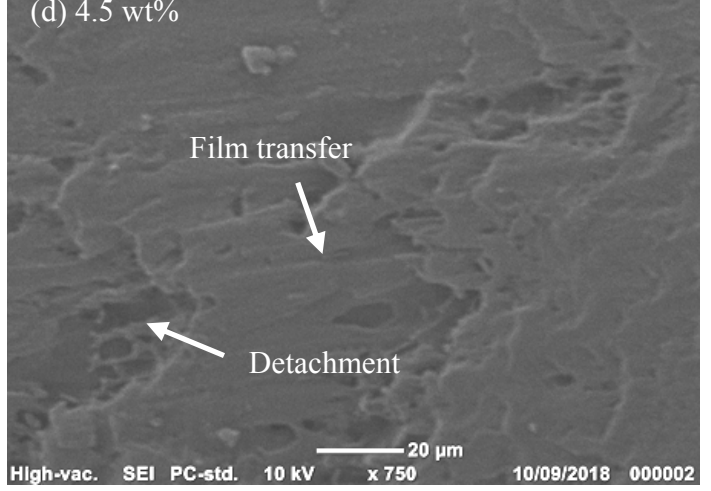

Fig. 15 SEM micrographs of epoxy and its composites after adhesive at $30 \mathrm{~N}$ of the applied load.

section and in the light of our test data, we attempt to understand the effect of the different mechanical properties on epoxy's tribological performance. Figure 17 presents a plot of epoxy versus the weight fraction of GNPs in terms of the mechanical properties under investigation, fracture strength, stiffness, and hardness, as well as the tribological properties of COF and $W_{\mathrm{s}}$. To involve the effect of the applied load on the correlation study, the intermediate applied load of $30 \mathrm{~N}$, and the highest applied load of $60 \mathrm{~N}$ are considered, as shown in Figs. 17(a) and 17(b).

Regarding the effect of the individual mechanical properties on the COF, it is clear that there is no significant correlation between them. The trend of COF with respect to the GNP content stays similar at both applied loads. This is because $\mathrm{COF}$, in this case, is highly influenced by the transfer film process, which, in turn, is affected by the content of GNPs. In other words, COF is mainly dependent on the surface properties of the rubbing surfaces, and the interface temperature at the contact zone [11, 48]. In contrast, Alajmi and Shalwan [49] reported that COF was directly related to mechanical properties; however, their analysis was a statistical point of view.

The specific wear rate is sensitive to the brittle behaviours of the epoxy-GNP composites, especially at a high applied load. The GNPs' addition may accelerate the brittle fracture of epoxy---resulting in higher fatigue stress. Higher additions of GNPs have been shown to lead to reduced toughness, strength, and failure strain of epoxy, which also leads to lowering its load-bearing capacity [3]. Rasheva et al. [48] studied the relation between the mechanical and tribological properties of carbon fibre reinforced PEEK. They stated that strength and stiffness do not necessarily correspond to higher wear resistance. Chand et al. [50] studied the correlation between wear resistance and the mechanical properties of polyethene reinforced by treated and untreated silane fibre. Their results showed a linear relation in the case of treated fibre, and, in 


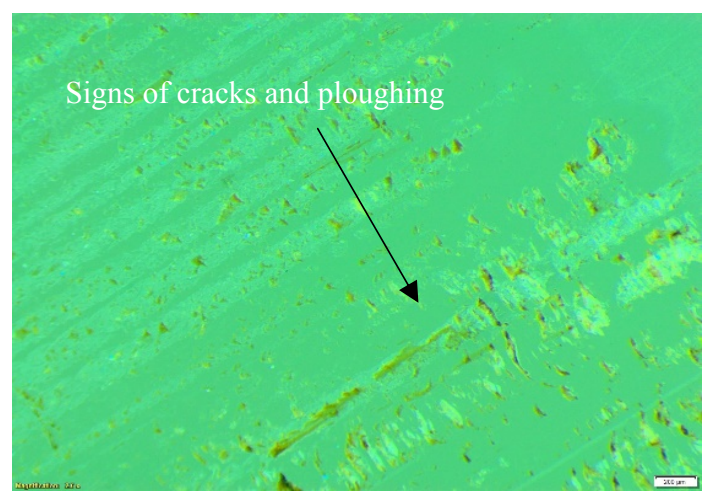

(a) Neat epoxy

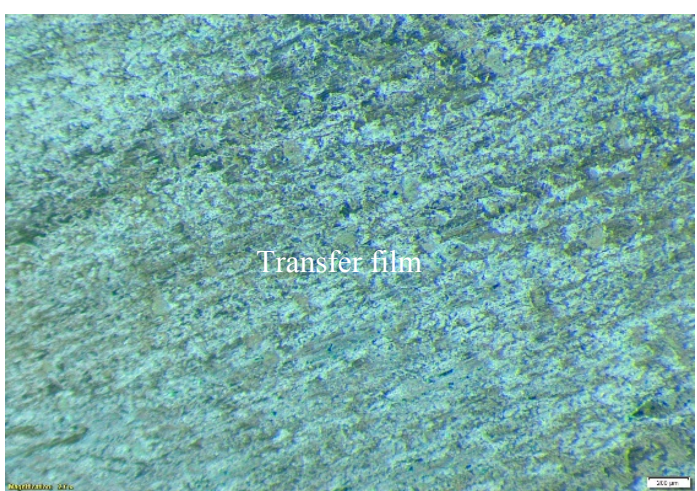

(b) Epoxy-GNPs-4.5

(c) Steel counterface in the case of epoxy-GNPs composites

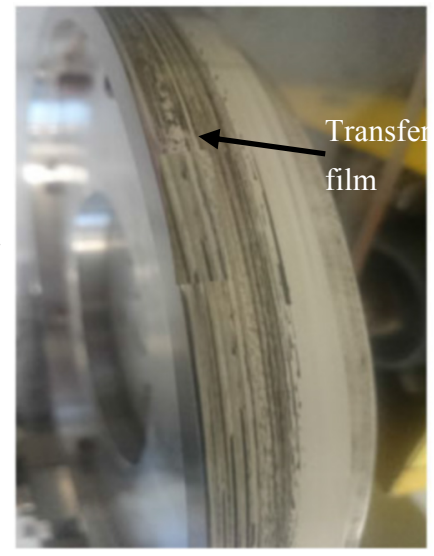

Fig. 16 Micrographs for the worn suraces of (a) neat epoxy and (b) epoxy-GNPs-4.5 composite, and (c) optical camera photo of the transfer film covered steel counterface in the case of GNPs addition.

contrast, no noticeable relation in the case of untreated fibre. In another study, Alajmi and Shalwan [49] showed no noticeable correlation between both properties; however, the study did not take consideration the influence of the applied load.

It must be kept in mind that the wear process is very complex and could affect the bulk's mechanical properties. For instance, wear is accompanied by frictional heat that could significantly affect mechanical properties such as stiffness and hardness. At a higher applied load, the deformation of epoxy composites becomes plastic rather than elastic, due to the increase of interface temperature. It is worth mentioning here that a polymer's deformation remains elastic unless reaching the polymer's softening temperature [10]. At a high applied load, there are intense thermo-mechanical stresses-resulting in cracking the physical bonds between the epoxy and GNPs. At a high concentration of GNP, the possibilities are much greater due to the aggregation phenomenon. Therefore, it is often recommended to find the optimal content of nanofillers to avoid such defects. Overall, the correlation between the mechanical and tribological properties is somehow dependent on the operating parameters.

\section{Conclusions}

Epoxy composites based on different weight fractions of graphene nanoplatelets, $0-4.5 \mathrm{wt} \%$, were fabricated. The mechanical properties were evaluated, and the dry adhesive wear performance for all composites was investigated against a stainless steel counterface using the BOR machine. The main findings can be summarised in the following points:

1) From the XRD and FTIR results, it was found 

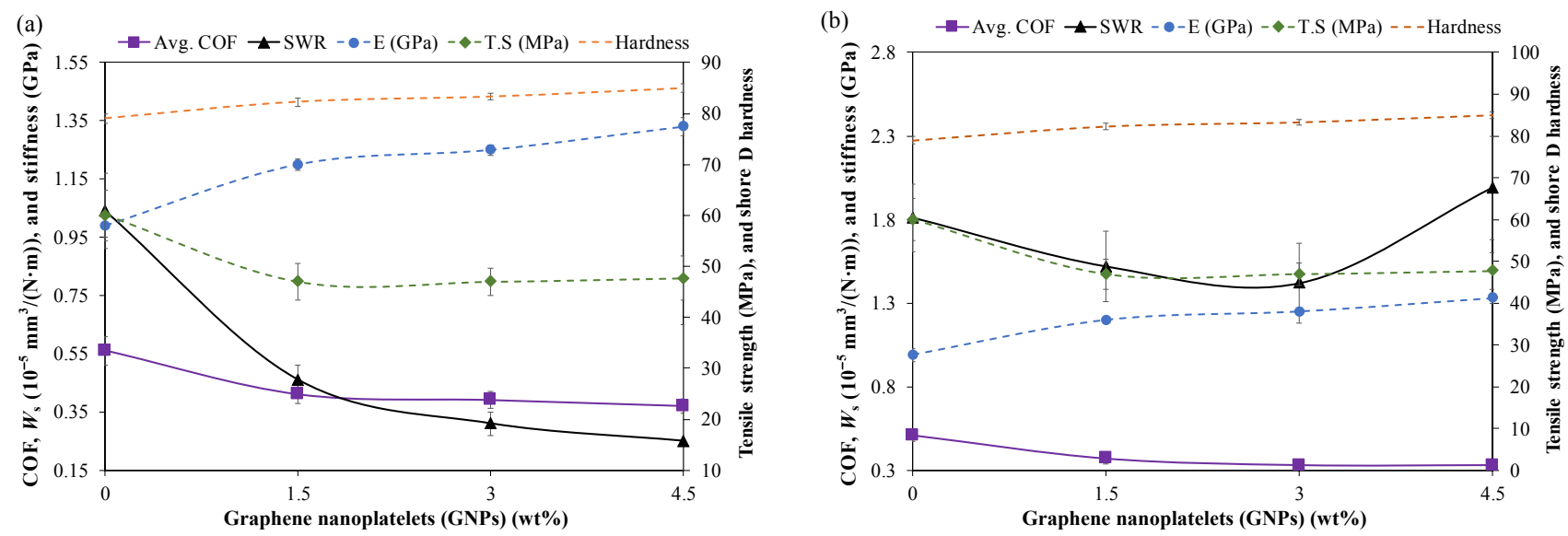

Fig. 17 Tribological (solid lines) and mechanical (dash lines) properties of epoxy-GNP composites: (a) $30 \mathrm{~N}$ and (b) $60 \mathrm{~N}$ of applied loads.

that epoxy has a physical interaction with GNPs which enhances the mechanical properties of composites (stiffness).

2) GNPs' addition increased epoxy's stiffness and hardness, while it reduced its tensile strength, toughness, and the fracture strain.

3) GNPs' addition showed a good ability to reduce friction and enhance the wear performance of the epoxy. For instance, a $4.5 \mathrm{wt} \%$ of GNPs decreased the COF and $W_{s}$ of epoxy by $36 \%$ and $75 \%$, respectively. Moreover, it has a positive impact on dissipating the heat generation at the wear contact zone, indicated by a lower interface temperature, compared with neat epoxy.

4) The correlation study between the mechanical and tribological behaviours revealed no strong relationship. However, at a higher applied load, brittleness corresponding with the increase of GNPs' content had an adverse impact on wear performance by increasing the wear rate.

Finally, our study suggests that the optimum amount of GNPs in the epoxy should be less than $4.5 \mathrm{wt} \%$, which can reduce the COF and $W_{\mathrm{s}}$ with less possibility of nanofiller aggregation. Yet this low level of GNPs in epoxy also reduced the fatigue wear mechanism, which is not desirable with materials that have a brittle nature like epoxy. The study also shows the importance of using polymers that have a high heat distortion temperature in tribological applications. It is recommended here that reinforcing polymer nanocomposites with fibres can improve their mechanical properties and thus their load-bearing capacity.

\section{Acknowledgements}

The first author is thankful for the Ph.D. scholarship sponsored by Tafila Technical University, Tafila, Jordan. The assistance from technicians and colleagues in the Centre of Future Materials is acknowledged.

Open Access This article is licensed under a Creative Commons Attribution 4.0 International License, which permits use, sharing, adaptation, distribution and reproduction in any medium or format, as long as you give appropriate credit to the original author(s) and the source, provide a link to the Creative Commons licence, and indicate if changes were made.

The images or other third party material in this article are included in the article's Creative Commons licence, unless indicated otherwise in a credit line to the material. If material is not included in the article's Creative Commons licence and your intended use is not permitted by statutory regulation or exceeds the permitted use, you will need to obtain permission directly from the copyright holder.

To view a copy of this licence, visit http://creativecommons.org/licenses/by/4.0/. 


\section{References}

[1] Li Y L, Wang S J, He E Q, Wang Q. The effect of sliding velocity on the tribological properties of polymer/carbon nanotube composites. Carbon 106: 106-109 (2016)

[2] Friedrich K. Polymer composites for tribological applications. Adv Ind Eng Polym Res 1(1): 3-39 (2018)

[3] Briscoe B J, Sinha S K. Tribological applications of polymers and their composites: Past, present and future prospects. Tribol Interface Eng Ser 55: 1-14 (2008)

[4] TriStar Plastics Corp. Composite bearings enable robotics innovation. 2019. Available at https://www.tstar.com/robotics.

[5] Kumar V, Sinha S K, Agarwal A K. Tribological studies of epoxy composites with solid and liquid fillers. Tribol Int 105: 27-36 (2017)

[6] Wang F Z, Drzal L T, Qin Y, Huang Z X. Mechanical properties and thermal conductivity of graphene nanoplatelet/epoxy composites. $J$ Mater Sci 50(3): 1082-1093 (2015)

[7] García P G, Ramírez-Aguilar R, Torres M, Franco-Urquiza E A, May-Crespo J, Camacho N. Mechanical and thermal behavior dependence on graphite and oxidized graphite content in polyester composites. Polymer 153: 9-16 (2018)

[8] Puértolas J A, Castro M, Morris J A, Ríos R, Ansón-Casaos A. Tribological and mechanical properties of graphene nanoplatelet/PEEK composites. Carbon 141: 107-122 (2019)

[9] Tahir N A M, Abdollah M F B, Hasan R, Amiruddin H. The effect of temperature on the tribological properties of palm kernel activated carbon-epoxy composite. Tribol Online 10(6): 428-433 (2015)

[10] Lancaster J K. Relationships between the wear of polymers and their mechanical properties. Proc Inst Mech Eng, Conf Proc 183(16): 98-106 (1968)

[11] Arhaim Y H, Shalwan A, Yousif B F. Correlation between frictional force, interface temperature and specific wear rate of fibre polymer composites. Adv Mater Res 685: 45-49 (2013)

[12] Dotson J D. The effects of high temperature on epoxy. 2018. Available at https://sciencing.com/effects-high-temperatureepoxy-8590977.html.

[13] [13] Masood M T, Papadopoulou E L, Heredia-Guerrero J A, Bayer I S, Athanassiou A, Ceseracciu L. Graphene and polytetrafluoroethylene synergistically improve the tribological properties and adhesion of nylon 66 coatings. Carbon 123: 26-33 (2017)

[14] Friedrich K, Schlarb A K. Tribology of Polymeric
Nanocomposites: Friction and Wear of Bulk Materials and Coatings. New York (USA): Elsevier, 2008.

[15] Ye Y P, Chen J M, Zhou H D. An investigation of friction and wear performances of bonded molybdenum disulfide solid film lubricants in fretting conditions. Wear 266(7-8): 859-864 (2009)

[16] Pan C, Kou K C, Zhang Y, Li Z Y, Wu G L. Enhanced through-plane thermal conductivity of PTFE composites with hybrid fillers of hexagonal boron nitride platelets and aluminum nitride particles. Compos Part B: Eng 153: 1-8 (2018)

[17] Puértolas J A, Kurtz S M. Evaluation of carbon nanotubes and graphene as reinforcements for UHMWPE-based composites in arthroplastic applications: A review. $J$ Mech Behav Biomed Mater 39: 129-145 (2014)

[18] Nirmal U, Hashim J, Ahmad M M H M. A review on tribological performance of natural fibre polymeric composites. Tribol Int 83: 77-104 (2015)

[19] Murugan S, Rai S K, Kumar P, Jayakumar T, Raj B, Bose M S C. Temperature distribution and residual stresses due to multipass welding in type 304 stainless steel and low carbon steel weld pads. Int J Press Vessels Piping 78(4): 307-317 (2001)

[20] Chin C W, Yousif B F. Potential of kenaf fibres as reinforcement for tribological applications. Wear 267(9-10): 1550-1557 (2009)

[21] El-Sayed A A, El-Sherbiny M G, Abo-El-Ezz A S, Aggag G A. Friction and wear properties of polymeric composite materials for bearing applications. Wear 184(1): 45-53 (1995)

[22] Shalwan A, Yousif B F. Influence of date palm fibre and graphite filler on mechanical and wear characteristics of epoxy composites. Mater Des 59: 264-273 (2014)

[23] Salom C, Prolongo M G, Toribio A, Martínez-Martínez A J, de Cárcer I A, Prolongo S G. Mechanical properties and adhesive behavior of epoxy-graphene nanocomposites. Int $J$ Adh Adhes 84: 119-125 (2018)

[24] Li Y Q, Umer R, Isakovic A, Samad Y A, Zheng L X, Liao $\mathrm{K}$. Synergistic toughening of epoxy with carbon nanotubes and graphene oxide for improved long-term performance. RSC Adv 3(23): 8849-8856 (2013)

[25] Qin W Z, Chen C, Zhou J P, Meng J Y. Synergistic effects of graphene/carbon nanotubes hybrid coating on the interfacial and mechanical properties of fiber composites. Materials 13(6): 1457 (2020)

[26] Atif R, Shyha I, Inam F. Mechanical, thermal, and electrical properties of graphene-epoxy nanocomposites-A review. 
Polymers 8(8): 281 (2016)

[27] Pedrazzoli D, Pegoretti A, Kalaitzidou K. Synergistic effect of exfoliated graphite nanoplatelets and short glass fiber on the mechanical and interfacial properties of epoxy composites. Compos Sci Technol 98: 15-21 (2014)

[28] Yousif B F, El-Tayeb N S M. Adhesive wear performance of T-OPRP and UT-OPRP composites. Tribol Lett 32(3): 199-208 (2008)

[29] Akpan E I, Wetzel B, Friedrich K. A fully biobased tribology material based on acrylic resin and short wood fibres. Tribol Int 120: 381-390 (2018)

[30] Hashmi S A R, Dwivedi U K, Chand N. Graphite modified cotton fibre reinforced polyester composites under sliding wear conditions. Wear 262(11-12): 1426-1432 (2007)

[31] Li P P, Zheng Y P, Li M Z, Shi T, Li D W, Zhang A B. Enhanced toughness and glass transition temperature of epoxy nanocomposites filled with solvent-free liquid-like nanocrystal-functionalized graphene oxide. Mater Des $\mathbf{8 9}$ : 653-659 (2016)

[32] Wang J G, Ma F C, Sun M T. Graphene, hexagonal boron nitride, and their heterostructures: Properties and applications. RSC Adv 7(27): 16801-16822 (2017)

[33] Liu J, Wang C, Liang T X, Lai W S. Interaction of boron with graphite: A van der Waals density functional study. Appl Surf Sci 379: 402-410 (2016)

[34] Jotaki K, Miyatake M, Stolarski T, Sasaki S, Yoshimoto S. Tribological performance of natural resin urushi containing PTFE. Tribol Int 113: 291-296 (2017)

[35] Rabinowicz E, Chan P. Wear of silver-graphite brushes against various ring materials at high-current densities. IEEE Trans Compon, Hybrids, Manuf Technol 3(2): 288-291 (1980)

[36] Baptista R, Mendão A, Rodrigues F, Figueiredo-Pina C G, Guedes M, Marat-Mendes R. Effect of high graphite filler contents on the mechanical and tribological failure behavior of epoxy matrix composites. Theor Appl Fract Mech 85: 113-124 (2016)

[37] Fu Y X, He Z X, Mo D C, Lu S S. Thermal conductivity enhancement of epoxy adhesive using graphene sheets as additives. Int J Therm Sci 86: 276-283 (2014)

[38] Li A, Zhang C, Zhang Y F. Thermal conductivity of graphene-polymer composites: Mechanisms, properties, and applications. Polymers 9(9): 437 (2017)

[39] Chatterjee S, Wang J W, Kuo W S, Tai N H, Salzmann C, Li W L, Hollertz R, Nüesch F A, Chu B T T. Mechanical reinforcement and thermal conductivity in expanded graphene nanoplatelets reinforced epoxy composites. Chem Phys Lett 531: 6-10 (2012)

[40] Ribeiro H, Silva W M, Rodrigues M T F, Neves J C, Paniago R, Fantini C, Calado H D R, Seara L M, Silva G G. Glass transition improvement in epoxy/graphene composites. J Mater Sci 48(22): 7883-7892 (2013)

[41] Hu Y Z, Shen J F, Li N, Ma H W, Shi M, Yan B, Huang W S Wang W B, Ye M X. Comparison of the thermal properties between composites reinforced by raw and amino-functionalized carbon materials. Compos Sci Technol 70(15): 2176-2182 (2010)

[42] Zaman I, Phan T T, Kuan H C, Meng Q S, La L T B, Luong L, Youssf O, Ma J. Epoxy/graphene platelets nanocomposites with two levels of interface strength. Polymer 52(7): 1603-1611 (2011)

[43] Bortz D R, Heras E G, Martin-Gullon I. Impressive fatigue life and fracture toughness improvements in graphene oxide/epoxy composites. Macromolecules 45(1): 238-245 (2012)

[44] Yousif B F, Lau S T W, McWilliam S. Polyester composite based on betelnut fibre for tribological applications. Tribol Int 43(1-2): 503-511 (2010)

[45] Zhang H J, Zhang Z Z, Guo F, Jiang W, Liu W M. Study on the tribological behavior of hybrid $\mathrm{PTFE} /$ cotton fabric composites filled with $\mathrm{Sb}_{2} \mathrm{O}_{3}$ and melamine cyanurate. Tribol Int 42(7): 1061-1066 (2009)

[46] Yallew T B, Kumar P, Singh I. Sliding wear properties of jute fabric reinforced polypropylene composites. Proc Eng 97: 402-411 (2014)

[47] Wei J C, Vo T, Inam F. Epoxy/graphene nanocompositesprocessing and properties: A review. RSC Adv 5(90): 73510-73524 (2015)

[48] Rasheva Z, Zhang G, Burkhart T. A correlation between the tribological and mechanical properties of short carbon fibers reinforced PEEK materials with different fiber orientations. Tribol Int 43(8): 1430-1437 (2010)

[49] Alajmi M, Shalwan A. Correlation between mechanical properties with specific wear rate and the coefficient of friction of graphite/epoxy composites. Materials 8(7): 4162-4175 (2015)

[50] Chand N, Sharma P, Fahim M. Correlation of mechanical and tribological properties of organosilane modified cenosphere filled high density polyethylene. Mater Sci Eng: A 527(21-22): 5873-5878 (2010) 


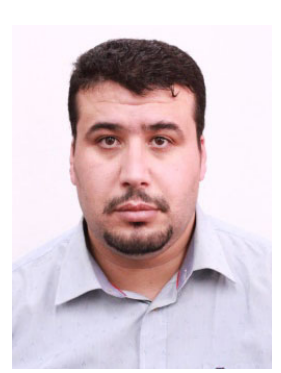

K. Y. EAYAL AWWAD. He received his M.S. degree in mechanical engineering from the University of Jordan, Amman, Jordan, in 2015. After that, he received his Ph.D. degree from the University of Southern Queensland (USQ), Toowoomba, Queensland, Australia, in 2020. After then, he joined the Mechanical Department as a full time lecturer at Tafila Technical University (TTU), Tafila, Jordan. His research areas cover solid lubricants, tribology, and wear mechanisms of nanocomposites and polymeric composites, natural fiber polymeric composites. In addition, his research interest includes grain refinement in alloys, micro-metal alloys, and severe plastic deformation (SPD). 